\title{
Functional Differentiation of a Population of Electrically Coupled Heterogeneous Elements in a Microcircuit
}

\author{
Kosei Sasaki, ${ }^{1}$ Elizabeth C. Cropper, ${ }^{1}$ Klaudiusz R. Weiss, ${ }^{1}$ and Jian Jing ${ }^{1,2}$ \\ ${ }^{1}$ Department of Neuroscience, Mount Sinai School of Medicine, New York, New York 10029, and ${ }^{2}$ School of Life Sciences, Nanjing University, Nanjing, \\ Jiangsu 210093, China
}

\begin{abstract}
Although electrical coupling is present in many microcircuits, the extent to which it will determine neuronal firing patterns and network activity remains poorly understood. This is particularly true when the coupling is present in a population of heterogeneous, or intrinsically distinct, circuit elements. We examine this question in the Aplysia californica feeding motor network in five electrically coupled identified cells, B64, B4/5, B70, B51, and a newly identified interneuron B71. These neurons exhibit distinct activity patterns during the radula retraction phase of motor programs. In a subset of motor programs, retraction can be flexibly extended by adding a phase of network activity (hyper-retraction). This is manifested most prominently as an additional burst in the radula closure motoneuron B8. Two neurons that excite B8 (B51 and B71) and one that inhibits it (B70) are active during hyper-retraction. Consistent with their near synchronous firing, B51 and B71 showed one of the strongest coupling ratios in this group of neurons. Nonetheless, by manipulating their activity, we found that B51 preferentially acted as a driver of B64/B71 activity, whereas B71 played a larger role in driving B8 activity. In contrast, B70 was weakly coupled to other neurons and its inhibition of B8 counteracted the excitatory drive to B8. Finally, the distinct firing patterns of the electrically coupled neurons were fine-tuned by their intrinsic properties and the largely chemical cross-inhibition between some of them. Thus, the small microcircuit of the Aplysia feeding network is advantageous in understanding how a population of electrically coupled heterogeneous neurons may fulfill specific network functions.
\end{abstract}

\section{Introduction}

For any given microcircuit to function properly, circuit elements have to generate specific activity patterns, which are determined by both synaptic connections and intrinsic properties of component neurons. Growing evidence suggests the importance of electrical coupling, which is present in many microcircuits in both invertebrates and vertebrates, and often serves to synchronize neural activity (Galarreta and Hestrin, 2001; Bennett and Zukin, 2004). As might be expected, many homogenous or intrinsically similar circuit elements, either homologous neurons that are bilaterally located or neurons of the same type (presumably with similar intrinsic properties), are electrically coupled. These homogenous neurons often have similar firing patterns during network activity, and electrical coupling may function to synchronize their activity. Indeed, electrical coupling between homogenous neurons has been relatively well studied, using both experimental and modeling techniques (Sherman and Rinzel, 1992, Jefferys, 1995; Chow and Kopell, 2000; Bennett and Zukin, 2004).

Although electrical coupling between heterogeneous or intrinsically distinct neurons appears to be less prevalent, it is pres-

\footnotetext{
Received Aug. 5, 2012; revised Sept. 12, 2012; accepted 0ct. 24, 2012.

Author contributions: K.S. and J.J. designed research; K.S. and J.J. performed research; K.S. and J.J. analyzed data; E.C.C., K.R.W., and J.J. wrote the paper.

This work was supported by NIH Grants NSO66587, NSO70583, and MH051393.

Correspondence should be addressed to Dr. Jian Jing, Department of Neuroscience, Box 1065, Mount Sinai School of Medicine, 1 Gustave Levy Place, New York, NY 10029. E-mail: jingj01@gmail.com.

DOI:10.1523/JNEUROSCI.3841-12.2013

Copyright $\odot 2013$ the authors $\quad 0270-6474 / 13 / 330093-13 \$ 15.00 / 0$
}

ent in invertebrate circuits (Johnson et al., 1993; Jing and Gillette, 1999; Jing and Weiss, 2001; Susswein et al., 2002; Kristan et al., 2005; Soto-Treviño et al., 2005; Sasaki et al., 2007; Nargeot et al., 2009; Jing et al., 2011; Roffman et al., 2012) and the mammalian spinal cord and cortex (Galarreta and Hestrin, 2001; Wilson et al., 2007). The functional role of this form of electrical coupling is less well understood, particularly when considering a population of, rather than two, heterogeneous circuit neurons. In part, this is a result of the fact that there are few experimentally amenable model systems where this type of coupling can be studied. A priori it might be expected that electrical coupling would serve to promote synchronous firing. However, modeling studies suggest that heterogeneity can influence network behavior in unintuitive ways (Kepler et al., 1990; Wilson and Callaway, 2000; SotoTreviño et al., 2005); e.g., it can destabilize synchronous behavior (De Vries et al., 1998). This raises two interesting and intriguing experimental questions: How does electrical coupling between heterogeneous neurons relate to (1) their activity patterns and (2) their network functions?

We sought to address these issues in an experimentally advantageous model system, i.e., the Aplysia feeding motor network (Cropper et al., 2004; Jing et al., 2009), where a population of five heterogeneous neurons is electrically coupled. These neurons, which include one newly identified interneuron, all show activity during the retraction phase. Their specific activity patterns differ, however. Moreover, they appear to have distinct network functions. In particular, we took advantage of the small number of circuit elements and determined the coupling strength between all pairs of neurons. We demonstrated the prevalence of asym- 
metrical electrical coupling between heterogeneous neurons. To our knowledge, there are few studies such as ours that characterize the activity patterns and network functions of microcircuits of heterogeneous electrically coupled neurons. Specifically, we were able to show that two strongly coupled neurons exhibit identical activity patterns during programs and excite the same motoneuron. Nonetheless, they appear to fulfill different network functions.

\section{Materials and Methods}

Experiments were performed on Aplysia californica (100-250 g) obtained from Marinus. Aplysia are hermaphroditic; i.e., each animal has reproductive organs normally associated with both male and female sexes. Animals were anesthetized by injection of isotonic $\mathrm{MgCl}_{2}(30-$ $50 \%$ of body weight). The cerebral and buccal ganglia were removed, desheathed (ventral surface of the cerebral ganglion, caudal surface of the buccal ganglion), and pinned in a recording chamber $\left(14-17^{\circ} \mathrm{C}\right.$; volume, $\sim 1 \mathrm{ml}$ ) perfused at $0.33 \mathrm{ml} / \mathrm{min}$. The composition of normal artificial seawater was as follows (in mM): $460 \mathrm{NaCl}, 10 \mathrm{KCl}, 11 \mathrm{CaCl}_{2}, 55 \mathrm{MgCl}_{2}$, and 10 HEPES, pH 7.6. To suppress polysynaptic pathways, a highdivalent cation saline was used [containing (in $\mathrm{mm}$ ) $368 \mathrm{NaCl}, 8 \mathrm{KCl}, 13.8$ $\mathrm{CaCl}_{2}, 115 \mathrm{MgCl}_{2}$, and 10 HEPES, pH 7.6]. All reagents were obtained from Sigma.

Electrophysiology. Initially, intracellular recordings were made using single-barrel electrodes (5-10 M $\Omega$ ) filled with $2 \mathrm{M} \mathrm{K}$-acetate and $30 \mathrm{~mm}$ $\mathrm{KCl}$. Later experiments used electrodes (5-10 M $\Omega$ ) filled with $0.6 \mathrm{M}$ $\mathrm{K}_{2} \mathrm{SO}_{4}$ plus $60 \mathrm{~mm} \mathrm{KCl}$. Intracellular signals were acquired using an AxoClamp 2B amplifier (MDS Analytical Technologies) or a Getting model 5A amplifier. Extracellular signals were acquired from polyethylene suction electrodes using a differential alternating current amplifier (model 1700; A-M Systems). A Grass stimulator model S88 (Grass Instruments) was used for stimulation.

The B71 interneuron is described here for the first time (see Results). All other neurons were identified as described previously (Plummer and Kirk, 1990; Rosen et al., 1991; Hurwitz et al., 1994, 1997; Hurwitz and Susswein, 1996; Jing and Weiss, 2001; Sasaki et al., 2009). The morphology of B71 was determined by injection of Alexa 488 or Alexa 568. To allow the dye to diffuse from the buccal ganglion to the cerebral ganglion, we incubated the ganglion after dye injection in the refrigerator $\left(4-8^{\circ} \mathrm{C}\right)$ overnight.

Motor programs and hyper-retraction. Each cycle of the Aplysia feeding motor programs consists of two phases, a radula protraction phase followed by a radula retraction phase (see Fig. 1). Motor programs can be elicited through stimulation of higher-order interneurons, cerebral-buccal interneuron-2 (CBI-2) (Rosen et al., 1991; Jing and Weiss, 2001), CBI-12 (Jing and Weiss, 2005), and CBI-4 (Jing et al., 2004). Often, in motor programs elicited by CBI-4 (Jing et al., 2004), the retraction phase is followed by an additional burst of activity present in radula closure motoneuron B8 and other neurons (e.g., B51), termed hyper-retraction (see Fig. 1A) (Morton and Chiel, 1993a,b; Evans and Cropper, 1998; Jing et al., 2004). Behaviorally, hyper-retraction is believed to be important when the animals successfully grasp food object and may serve to move the food object deeper into the buccal cavity, e.g., during swallowing or bite swallowing (Evans and Cropper, 1998; Jing et al., 2004). The second part of this paper investigates how B8 activity during hyper-retraction is controlled by interneurons in the feeding microcircuit.

The buccal central pattern generator $(\mathrm{CPG})$ microcircuit generates several types of motor programs. The major components of these programs are protraction-retraction and opening-closing movements of the radula. Regardless of the type of motor program, the protractionretraction sequence remains constant. Protraction was monitored by recording from the I2 nerve, which contains the axons of protractor motoneurons B31/32 (Hurwitz et al., 1994). In some experiments, retraction was monitored by recording from the buccal nerve 2 , which contains the axons of retractor motoneurons. In other experiments, retraction was monitored by the sustained depolarization of the radula closing motoneuron B8 following protraction. In contrast to the phase invariance of the protraction-retraction sequence, the timing of radula opening and closing depends on the type of program (Morton and Chiel, 1993a,b; Church and Lloyd, 1994; Nargeot et al., 1997; Jing and Weiss, 2001; Morgan et al., 2002; Jing et al., 2010; Wu et al., 2010). Briefly, when B8 fires predominantly during retraction, and thus (in the intact animal) helps bring the food into the buccal cavity, the program is considered to be ingestive. When B8 fires predominantly during protraction, and thus helps in removing an inedible object from the buccal cavity, the program is considered to be egestive. When B8 fires during both protraction and retraction, programs are defined as intermediate.

In this study, motor programs were elicited via intracellular stimulation of higher-order neurons, including CBI-2 at $\sim 10 \mathrm{~Hz}$ and CBI- 4 at $\sim 15 \mathrm{~Hz}$. Each current pulse was set to trigger a single action potential. Stimulation of CBIs was manually terminated after the protraction phase ended as determined by activity in the I 2 nerve.

Data analysis. Electrophysiological recordings were digitized online with AxoScope and plotted with CorelDraw. Spike width was defined as the duration of the spike at half height, and the measurement of the spike width was automatically performed off-line using Clampfit software. Bar graphs were plotted using Axum (MathSoft). Data are expressed as mean \pm SEM. Statistical tests were performed using Prism (GraphPad Software). They included Student's $t$ test and repeated-measures oneway ANOVA, which were applied as was appropriate. Data that showed significant effects in ANOVA were analyzed further in individual comparisons with Bonferroni's correction. In all statistical tests, effects were considered statistically significant when $p<0.05$.

\section{Results}

The core of the central pattern generator microcircuit that generates Aplysia motor patterns consists of two major classes of neurons: protraction and retraction neurons. In this report, we focus on retraction neurons. Retraction neurons are of interest because previous work (Plummer and Kirk, 1990; Hurwitz and Susswein, 1996; Evans and Cropper, 1998; Baxter and Byrne, 2006; Sasaki et al., 2009) indicated that many, if not all, neurons that are active during retraction (including the flexibly added hyper-retraction; see Materials and Methods) are electrically coupled. These neurons include B64, B4/5, B70, and B51. Interestingly, despite this electrical coupling, these neurons do not exhibit identical firing patterns (Fig. 1A). This suggests they may differ in intrinsic properties and/or synaptic inputs. For example, the plateau-generating retraction interneuron B64 is active throughout retraction and hyper-retraction (Jing et al., 2004). $\mathrm{B} 4 / 5$ is active during the early part of retraction, while B70 is active during the later part of retraction (Sasaki et al., 2009). In contrast, B51 is only active during hyper-retraction (Evans and Cropper, 1998; Jing et al., 2004). Thus, these retraction neurons constitute an example of a circuit that contains heterogeneous electrically coupled neurons.

Here, we identify a novel retraction neuron, termed B71, that is only active during hyper-retraction. Paired recording of B71 and B51 showed that the activity pattern of B71 was similar to that of B51 (Fig. 1B). During protraction, both B71 and B51 primarily received IPSPs that hyperpolarized them. During retraction, there was a gradual buildup of depolarization in the absence of discrete EPSPs, presumably partly resulting from the extensive electrical coupling within the retraction circuitry. Indeed, B71 was electrically coupled, to various degrees, to all the buccal retraction neurons that we tested, including B51, B64 (Fig. 2), B4/5, $\mathrm{B} 70$, and B21.

The similarity between the B51 and B71 firing patterns raised the question of whether they may have similar intrinsic properties and/or have similar synaptic connections. As a first step toward answering this question, we examined B71 morphology by intracellular dye injection. B71 is a medium-sized cell of $80-110$ $\mu \mathrm{m}$ in diameter. There are two B71s in the buccal ganglion, which 

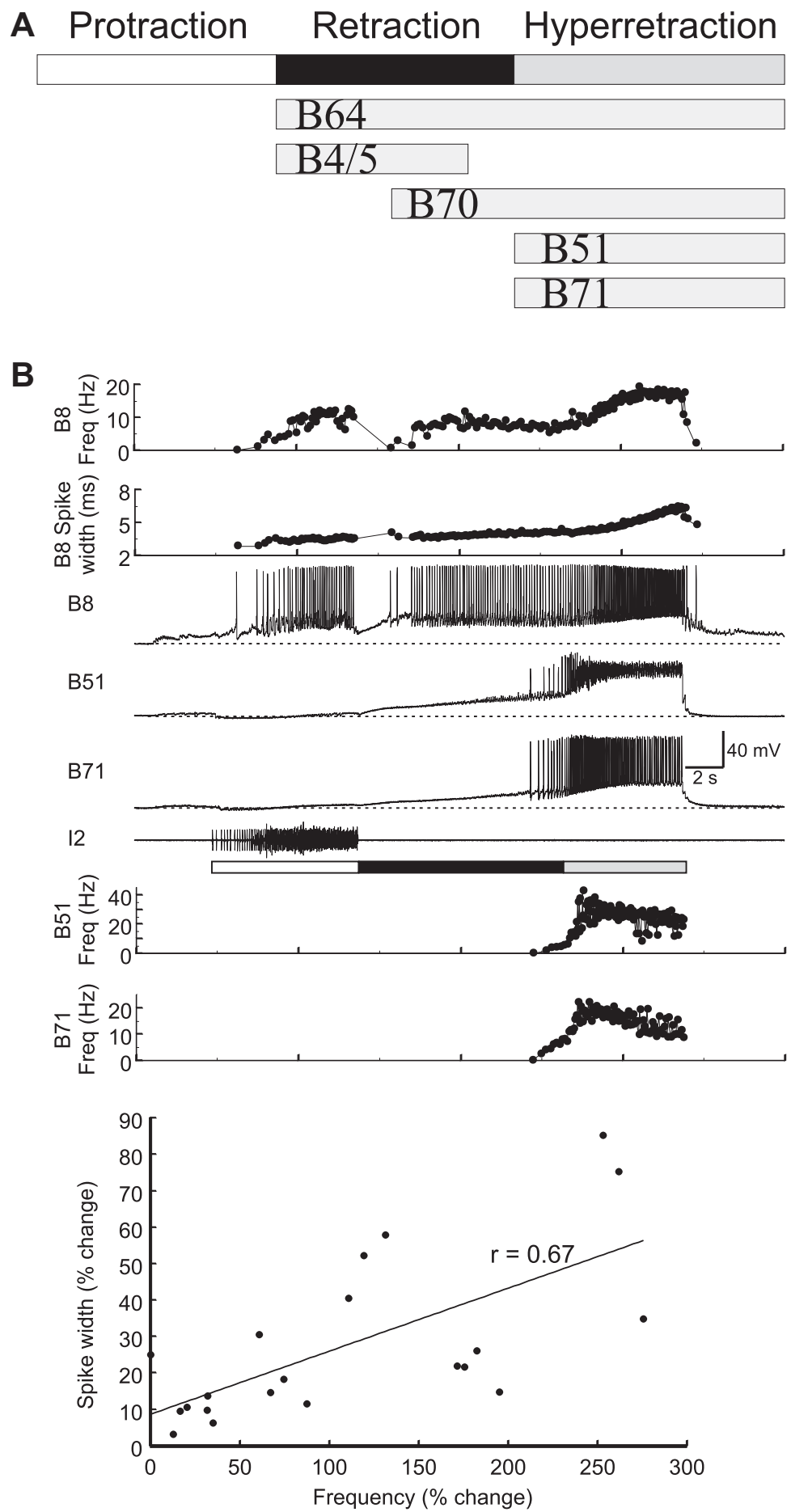

Figure 1. Activity phasing of neuronal elements within the retraction circuit. $A$, Schematic representations of activity phasing of neurons in a single cycle. Each cycle of a motor program consists of protraction (open bar) followed by retraction (filled bar). In a subset of programs, as illustrated here, hyper-retraction (gray bar) is added on to the retraction phase. Five retraction neurons, $B 64, B 4 / 5, B 70, B 51$, and $B 71$, show various activity patterns during retraction and hyper-retraction. $B$, In a single cycle of a program elicited by CBI-4 (data not shown), B51 and B71 showed similar activity patterns during hyper-retraction, accompanied by strong firing in B8. The bottom graph shows that increasing firing frequency (\% change) and spike width (\% change) of B8 during hyper-retraction ( $n=21$ ) are positively correlated. Line, Linear regression line; $r$, correlation coefficient. Protraction (open bar) is marked by 12 activity. Freq, Frequency.

are electrically coupled (coupling ratio, $0.073 \pm 0.006 ; n=8$ ). The two B71s differ from most other homologous neurons that have been identified in Aplysia, which are located bilaterally in the two hemiganglia. In contrast, both B71s are present on the same side (right). They are located in the ventral motoneuron cluster near the commissure, in the vicinity of the B4/5 neurons (Fig. $3 A, C)$. To verify that both $\mathrm{B} 71$ s are at the right side, we identified two neurons that have the physiological characteristics (spike height, firing patterns, synaptic connections, etc.) similar to B71. We then injected one cell with Alexa 488 (Fig. $3 A, B$ ), and the other with Alexa 568 (Fig. $3 C-H)$, and showed that both cells had similar morphology under a Nikon fluorescence microscope with appropriate filters.

B71 is a bipolar cell with two axons (Fig. $3 A-D$ ), one axon projecting to the ipsilateral cerebral-buccal connective (CBC) and the other crossing the commissure and projecting to the contralateral CBC. Within the buccal ganglion, fine processes arborize extensively in the neuropile along the axons. Both B71 axons enter the cerebral ganglion through bilateral CBCs and ramify more locally near the root of the CBCs in the cerebral ganglion (Fig. $3 E-H$ ). B71 axons do not exit the buccal or the cerebral ganglion through peripheral nerves; thus B71 is a buccal-cerebral interneuron with bilateral innervation of the cerebral ganglion, similar to the B20 interneuron (Teyke et al., 1993). The morphological characteristics of B71 indicate it is different from B51, which has a peripheral axon in the radula nerve, and subserves a sensory function (Evans and Cropper, 1998). Thus, it is possible that B51 and B71 are intrinsically different, and may be tentatively considered as heterogeneous members of the electrically coupled retraction circuit.

\section{Electrical and chemical connections within retraction circuitry}

The activity patterns of the five retraction neurons differ, but the activity patterns of some neuron pairs, i.e., between B51 and $\mathrm{B} 71$, are more similar to each other than to other neurons (Fig. 1A). Given that electrical coupling generally promotes synchronous firing of coupled neurons (Galarreta and Hestrin, 2001; Bennett and Zukin, 2004), we hypothesized that the difference in firing patterns may be related to the difference in coupling strength, and that the neurons with similar patterns would have stronger coupling.

To test this hypothesis, we measured steady-state electrical coupling ratios between all five neuron pairs. Although electrical coupling between neurons other than B71 has been described previously, most of the coupling ratios have not been reported. Analyses of coupling ratios (Fig. 4A; 


\section{A1}

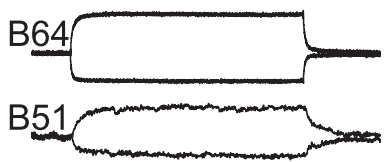

A2

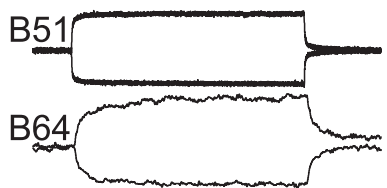

B1

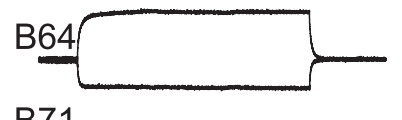

B71

B2

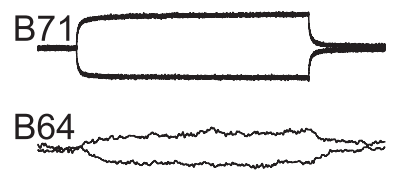

C1
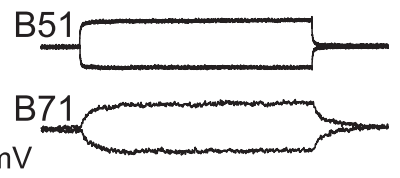

C2

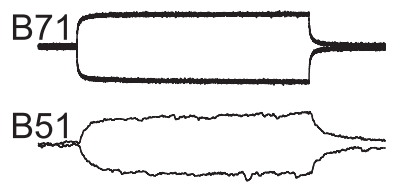

Figure 2. Electrical coupling between three neuronal elements (B64, $B 51$, and $B 71$ ) within the retraction circuit. $\boldsymbol{A} 1, \mathbf{A 2}$, From $B 64$ (both depolarizing and hyperpolarizing currents, $1.5 \mathrm{nA})$ to $B 51$ (A1), and from B51 (3nA) to B64 (A2); $n=4 . B 1, B 2$, From B64 (1.5 nA) to B71 (B1), and from B71 (2nA) to B64 (B2); $n=3$. C1, C2, From B51 (2 nA) to B71 (C1), and from B71 (2nA) to B51 (C2); $n=4$. For each panel, the top recordings show the presynaptic cells that were depolarized and hyperpolarized for $3 \mathrm{~s}$, and the bottom recordings show corresponding responses in the postsynaptic cells. Coupling ratios measured by depolarizing and hyperpolarizing pulses were similar, suggesting that these electrical synapses are nonrectifying. Note the different coupling strengths between the coupled pairs and asymmetrical coupling within the coupled pairs. Membrane potentials at the beginning of traces were as follows: $B 64,-62 \mathrm{mV} ; \mathrm{B} 51,-57 \mathrm{mV} ; \mathrm{B} 71,-55 \mathrm{mV}$.
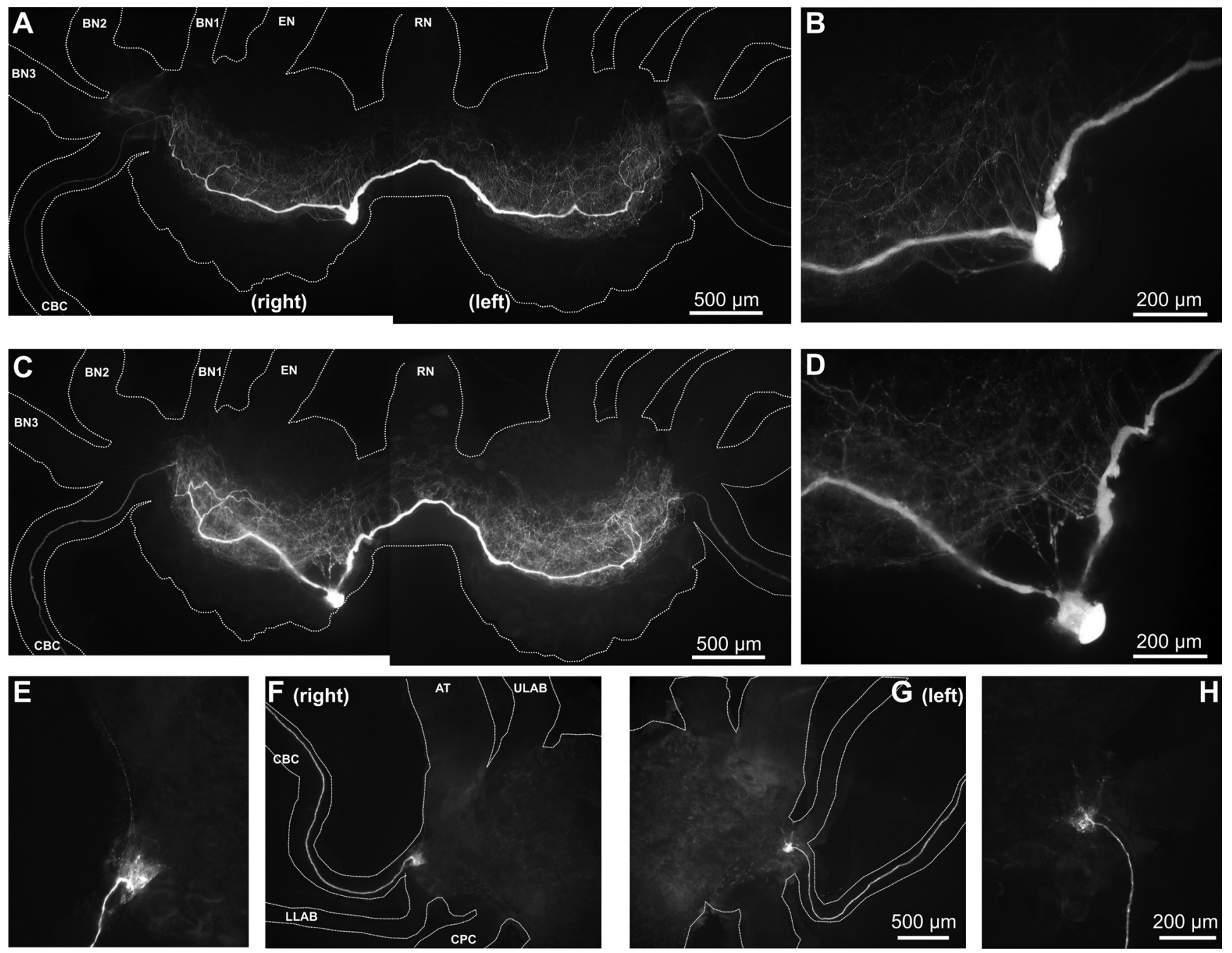

Figure 3. The two $B 71$ neurons are both located in the right side of the buccal ganglion. $A$, Photograph of the buccal ganglion shows that $B 71$, a bipolar interneuron, projects two axons bilaterally to the $C B C$ s. B71 was injected with Alexa 488 dye. $\boldsymbol{B}, \mathbf{B} 71$ soma area in higher magnification. $\mathbf{C}-\boldsymbol{H}$, The second B71 was injected with Alexa 568 dye. $\boldsymbol{C}, \boldsymbol{D}$, similar to $\boldsymbol{A}$ and $\boldsymbol{B}$, except they were from the second $B 71 . F, G$, Photographs of the right and left cerebral ganglion around the roots of the $C B C$, showing the second $B 71$ projections that enter the cerebral ganglion. $\boldsymbol{E}$, $\boldsymbol{H}$, Higher-magnification views of the $B 71$ axon terminals from the photographs in $\boldsymbol{F}$ and $\mathbf{G}$, respectively. Buccal ganglion (rostral side up): BN, buccal nerve; EN, esophageal nerve; RN, radula nerve. Cerebral ganglion (ventral side up): AT, anterior tentacular nerve; ULAB, upper labial nerve; LLAB, lower labial nerve. CPC, Cerebral-pedal connective. 
A

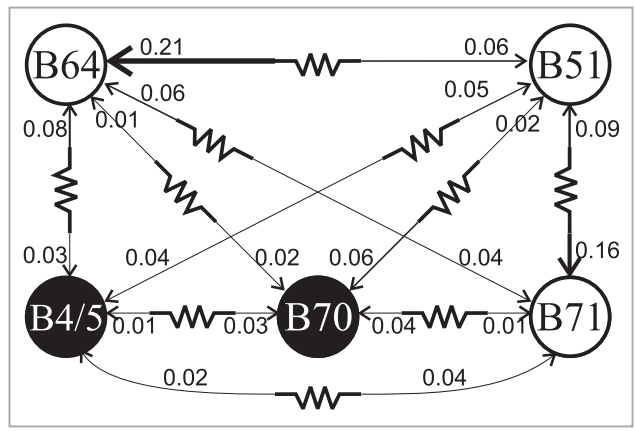

B

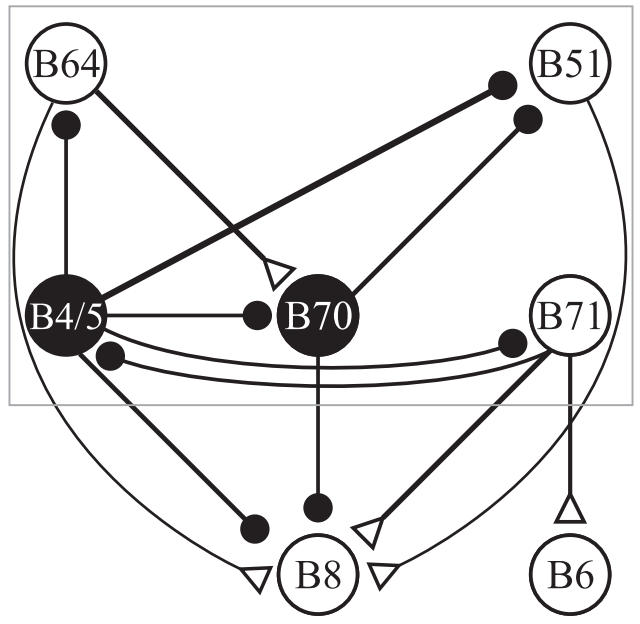

Figure 4. Schematic diagrams of synaptic connections of retraction circuitry neurons. $\boldsymbol{A}$, Electrical coupling showing the coupling ratios. Thickness of lines is proportional to coupling ratios. $B$, Chemical connections. Also illustrated are connections to motoneurons B8 and B6. Two neurons, B4/5 and B70, that inhibit B8 are shown in filled circles. Open triangles, Chemical excitation; closed circles, inhibition; resistor symbol, electrical coupling.

Table 1) revealed that the coupling between most pairs of neurons was not symmetrical, consistent with the idea that these neurons are heterogeneous. For example, between B51 and B64, the coupling ratio from B51 to B64 was stronger than the coupling ratio from $\mathrm{B} 64$ to $\mathrm{B} 51\left(0.209 \pm 0.032\right.$ vs $0.057 \pm 0.008, t_{(6)}$ $=6.19, p<0.001, n=7)$. In addition, electrical coupling between different neuron pairs differed. For the purpose of discussion, we refer to coupling ratios of $<0.04$ as weak, and those of $>0.07$ as strong. Consistent with near synchronous firing of B51 and B71, the coupling strength between them was one of the strongest $(0.16,0.09)$. B51 and, less so, B4/5 and B71 were strongly coupled to B64 $(0.21,0.08,0.06)$, which might promote the generation or maintenance of the $\mathrm{B} 64$ plateau during retraction. B51 and B71 also were moderately coupled to B70 (0.06, 0.04 ), and this might promote the initiation and maintenance of B70 activity during the later part of retraction. In contrast, the coupling from B70 to all other retraction neurons was weak (0.01-0.02). Finally, we also found that B71 was strongly electrically coupled to jaw closure motoneuron B6 (Church and Lloyd, 1994) (coupling ratios, from $B 71$ to $B 6,0.149 \pm 0.010$; from $B 6$ to B71, $\left.0.16 \pm 0.028, t_{(3)}=0.43, p>0.05, n=4\right)$.

The asymmetrical coupling could have resulted from differences in intrinsic properties of the coupled neurons or rectifying electrical coupling between them (Furshpan and Potter, 1959; Bennett, 1966; Johnson et al., 1993). Because rectifying electrical coupling passes current better in one direction, one of its hall- marks is that for two coupled neurons A and B, depolarizing current injected into A will produce larger responses in B than hyperpolarizing current injected into A. Furthermore, hyperpolarizing current injected into B will produce larger responses in A than depolarizing current in B (Furshpan and Potter, 1959; Marder, 2009). When we calculated coupling ratios shown in Figure $4 A$ and Table 1, we mostly applied only hyperpolarizing currents. To determine whether the asymmetrical coupling we observed in B64-B51, B64-B71, and B51-B71 pairs was due to rectifying electrical coupling, we applied both hyperpolarizing and depolarizing currents (Fig. 2). Coupling ratios derived using hyperpolarizing versus depolarizing currents were similar: from B64 to B51, $0.086 \pm 0.005$ versus $0.098 \pm 0.006\left(t_{(3)}=1.25, p>\right.$ $0.05)$, and from B51 to B64, $0.171 \pm 0.013$ versus $0.168 \pm 0.014$ $\left(t_{(3)}=0.51, p>0.05, n=4\right)$; from B64 to B71, $0.048 \pm 0.004$ versus $0.045 \pm 0.004\left(t_{(2)}=0.42, p>0.05\right)$, and from B71 to B64, $0.074 \pm 0.010$ versus $0.079 \pm 0.012\left(t_{(2)}=0.40, p>0.05, n=3\right)$; from B51 to B71, $0.155 \pm 0.009$ versus $0.152 \pm 0.008\left(t_{(3)}=0.30\right.$, $p>0.05)$, and from B71 to B51, $0.104 \pm 0.007$ versus $0.102 \pm$ $0.003\left(t_{(3)}=0.36, p>0.05, n=4\right)$. These data indicate that the asymmetrical coupling is not due to rectifying electrical coupling. In addition, our estimate of apparent input resistances of the three neurons (Fig. 5A) indicate that B51 has the lowest input resistance, which is significantly lower than input resistances of $\mathrm{B} 71$ and $\mathrm{B} 64\left(F_{(2,10)}=9.692, p<0.01, n=6\right)$. This suggests that the asymmetrical coupling between these neurons is, at least partly, due to differences in input resistance.

The coupling ratio data support the hypothesis that neurons with similar firing patterns tend to have high coupling ratios. However, there is at least one exception. Specifically, although B64 and B51 are coupled strongly, B64 started firing upon initiation of retraction, while B51 was only active during hyperretraction. Thus, we sought to identify other factors that might also influence the initiation of firing.

First, we measured spike thresholds of B64, B51, and B71. B64 had the lowest threshold, while $\mathrm{B} 51$ had the highest (Fig. $5 B ; F_{(2,6)}$ $=123.8, p<0.0001, n=4$ ). In addition, B64 has been described as a cell that generates plateau potentials (Hurwitz and Susswein, 1996). Importantly, we also found differences in chemical synaptic connections that may contribute to differences in firing patterns. All synaptic connections were examined in both normal saline and high-divalent saline, but to avoid redundancy, only one example from either experiment was selected for illustration purpose (Figs. 6, 7, 8A). In general, the chemical synaptic connections between the five retraction neurons are predominantly inhibitory (Fig. 6). Previous work has shown that B4/5 inhibits a number of retraction neurons, including motoneurons and B64, B51, B21, and B70 (Gardner, 1977; Plummer and Kirk, 1990; Rosen et al., 2000; Baxter and Byrne, 2006; Sasaki et al., 2009) (Fig. $4 B$ ). Here we found that B4/5 also inhibited B71 (Fig. 6A). The inhibitory connections from B4/5 to B70, B51, and B71 might help prevent the firing of these neurons during the early part of retraction. In contrast, the low spike threshold of B64 combined with its ability to generate a plateau potential of B64 might enable it to be the first retraction neuron to escape B4/5 inhibition to fire. It is notable that B51 also generates a plateau potential (Plummer and Kirk, 1990; Nargeot et al., 1999; Mozzachiodi et al., 2008), but its high spike threshold prevents it from firing early.

Although excitatory chemical connections are less common, there exists at least one such connection, from B64 to B70 (Sasaki et al., 2009). This connection may help B70 to escape inhibition from $\mathrm{B} 4 / 5$ to spike during the later part of retraction. We also 
Table 1. Electrical coupling ratios between retraction neurons

\begin{tabular}{llllll}
\hline Pre vs Post & B64 & B4/5 & B70 & B51 & B71 \\
\hline B64 & & $0.026 \pm 0.006\left(4^{* *}\right)$ & $0.018 \pm 0.005(4, \mathrm{~ns})$ & $0.057 \pm 0.008\left(7^{* * *}\right)$ & $0.041 \pm 0.008\left(4^{*}\right)$ \\
B4/5 & $0.082 \pm 0.006\left(4^{* *}\right)$ & & $0.029 \pm 0.005\left(5^{*}\right)$ & $0.046 \pm 0.004(4, \mathrm{~ns})$ & $0.044 \pm 0.003\left(4^{* *}\right)$ \\
B70 & $0.012 \pm 0.003(4, \mathrm{~ns})$ & $0.007 \pm 0.001\left(5^{*}\right)$ & & $0.016 \pm 0.002\left(5^{*}\right)$ & $0.011 \pm 0.002\left(3^{*}\right)$ \\
B51 & $0.209 \pm 0.032\left(7^{* * *}\right)$ & $0.043 \pm 0.011(4, \mathrm{~ns})$ & $0.056 \pm 0.013\left(5^{*}\right)$ & & $0.155 \pm 0.020\left(9^{* *}\right)$ \\
B71 & $0.063 \pm 0.014\left(4^{*}\right)$ & $0.024 \pm 0.001\left(4^{* *}\right)$ & $0.036 \pm 0.006\left(3^{*}\right)$ & $0.093 \pm 0.009\left(9^{* *}\right)$ & $0.073 \pm 0.006(8)$ \\
\hline
\end{tabular}

Numbers in parenthesis denote the number of preparations. ns, Not significant. The test results are as follows: B64 versus $B 4 / 5$ pair, $t_{(3)}=9.61, p<0.01, n=4 ; B 64$ versus $B 70$ pair, $t_{(3)}=1.75, p>0.05, n=4 ; B 64$ versus $B 51$ pair, $t_{(6)}=$ $6.19, p<0.001, n=7 ; B 64$ versus $B 71$ pair, $t_{(3)}=3.26, p<0.05, n=4 ; B 4 / 5$ versus $B 70$ pair, $t_{(4)}=4.46, p<0.05, n=5 ; B 4 / 5$ versus $B 51$ pair, $t_{(3)}=0.18, p>0.05, n=4 ; B 4 / 5$ versus $B 71$ pair, $t_{(3)}=6.9, p<0.01, n=4 ; B 70$ versus $B 51$ pair, $t_{(4)}=2.9, p<0.05, n=5 ; B 70$ versus $B 71$ pair, $t_{(2)}=4.97, p<0.05, n=3 ; B 51$ versus $B 71$ pair, $t_{(8)}=3.73, p<0.01, n=9$.

${ }^{*} p<0.05 ;{ }^{* *} p<0.01 ;{ }^{* * *} p<0.001$ (coupling ratios between paired neurons differ significantly, i.e., they are asymmetrical).
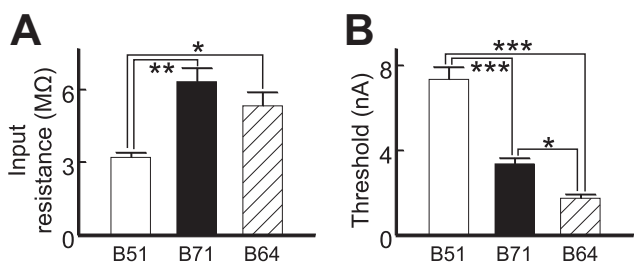

Figure 5. Intrinsic properties of $B 51, B 71$, and B64.A, Apparent input resistances $(n=6)$. $B$, Spike thresholds are the minimum depolarizing currents needed to induce spiking $(n=4)$. ${ }^{*} p<0.05 ;{ }^{* *} p<0.01 ;{ }^{* * *} p<0.001$ (Bonferroni post hoc tests). Error bars indicate SEM.

found that retraction neuron CBI-5/6 (Sasaki et al., 2007) excites B71 (Fig. 6B).

Finally, we examined the synaptic connectivity of B71 with protraction neurons. $\mathrm{B} 71$ received inhibition from protraction interneurons B63, B34, and B65 (Fig. 7A-C), providing a basis for the B71 hyperpolarization observed during protraction of motor programs (Fig. $1 B$ ). In turn, B71 also inhibited these protraction interneurons and protraction motoneurons B31/32 (Fig. 7D-F). Thus, B71 and protraction neurons are largely connected via mutual inhibition, which at least partially explains the absence of B71 activity during protraction. One notable synaptic connection that B71 makes with the protraction circuitry is that, in addition to the fast inhibition it induces, B71 also elicited a slow EPSP in $\mathrm{B} 63$ and $\mathrm{B} 31 / 32$. The slow EPSP was most obvious when $\mathrm{B} 71$ was stimulated for long periods (tens of seconds) (Fig. 7D).

To summarize, our results indicate that electrical coupling strength is an important factor in determining whether coupled heterogeneous neurons have similar network activity patterns. Additionally, however, other factors, such as intrinsic properties and synaptic connectivity, also contribute.

\section{Network functions: B71 and the hyper-retraction phase:}

We next sought to determine how electrical coupling in this group of neurons may relate to their network functions, e.g., their network output. We asked the following fundamentally important question: do the strongly coupled neurons that have similar activity patterns during network activity also have similar network functions? Indeed, studies that primarily study activity of neurons in different behaviors or network states often infer network functions of neurons based on their activity patterns.

Here, we focus on the network functions of B51 and B71. Although they differ in morphology, both B51 and B71 are strongly coupled and have similar activity patterns during the hyper-retraction phase of motor programs. Do these latter properties imply that B51 and B71 are also functionally similar? To address this issue, we examined the contributions of these two neurons to the activation of the radula closure motoneuron B8 during hyper-retraction.
Previous work has shown that B8 is a critical determinant of the type of motor program generated. B8 is active during both protraction and retraction phases of programs (Morton and Chiel, 1993a,b; Church and Lloyd, 1994; Nargeot et al., 1997; Jing and Weiss, 2001; Morgan et al., 2002; Jing et al., 2010; Wu et al., 2010). When $B 8$ is predominantly active during protraction, programs are egestive; when it is predominantly active during retraction, programs are ingestive. Relevant to the present study, B8 is also active during hyper-retraction, and therefore can be used as an important output neuron to examine the network functions of B51 and B71. We observed that when the hyper-retraction phase is present, B8 fired strongly, and its activity progressively increased as hyper-retraction progressed (Fig. $1 B$, first panel) (Jing et al., 2004, their Fig. 2). Because B8 activity showed a progressively higher firing frequency and previous work suggested that some neurons display frequency-dependent spike broadening (Ma and Koester, 1996), we measured B8 spike width (spike duration at half height; see Materials and Methods) and found that it also increased as hyper-retraction progressed (Fig. 1B, second panel). We quantified these changes during hyper-retraction in 21 cycles of CBI-4-elicited motor programs in 11 preparations. We determined that the initial frequency (average instantaneous frequency over the first three spikes, $4.03 \pm 0.42 \mathrm{~Hz}$ ) and peak frequency (average of the maximum instantaneous frequency and frequencies of two adjacent spikes, $8.66 \pm 1.11 \mathrm{~Hz}$ ) are significantly different $\left(t_{(20)}=5.57, p<0.0001, n=21\right)$. Spike width of the first spike ( $4.96 \pm 0.21 \mathrm{~ms})$ and the longest spike width $(6.31 \pm 0.34 \mathrm{~ms})$ are also significantly different $\left(t_{(20)}=5.48, p<\right.$ $0.0001, n=21$ ). We plotted firing frequency (percentage change) against spike width (percentage change) (Fig. 1, bottom) and showed that these two parameters are positively correlated (Pearson's $r=0.67, p<0.001)$.

Previous work (Plummer and Kirk, 1990; Evans and Cropper, 1998; Nargeot et al., 1999; Jing et al., 2004) has shown that one source of the excitatory input to B8 is likely to be B51, which elicits fast EPSPs in B8. Here, we found that B71 elicited both fast and slow EPSPs in B8 (Fig. $8 A ; n=25$ ). These data suggest a potential contribution of both B51 and B71 to B8 activity during hyper-retraction. To directly compare the specific contribution of each cell, we examined the ability of the two neurons to drive B8 activity. For this, we first quantified the firing rates of B51 and B71 during motor programs elicited by CBI-4: B51 fired at $21.05 \pm 0.73 \mathrm{~Hz}$, while B71 fired at $14.03 \pm 0.41 \mathrm{~Hz}\left(t_{(3)}=7.81\right.$, $p<0.0001, n=4$; Fig. $1 B$ ). To simulate normal firing rates of B51 and B71 during programs, we activated $\mathrm{B} 51$ at $20 \mathrm{~Hz}$, and B71 at $15 \mathrm{~Hz}(n=4$; Fig. $8 B)$. We found that B8 fired more when B71 was stimulated $(5.44 \pm 0.92 \mathrm{~Hz})$ than when $\mathrm{B} 51$ was stimulated $\left(1.75 \pm 0.17 \mathrm{~Hz}, t_{(3)}=4.71, p<0.05, n=4\right)$. In addition, when B71 was stimulated, the B8 firing frequency progressively increased, and B8 spikes broadened significantly (first spike, $4.53 \pm$ $0.23 \mathrm{~ms}$, vs the spike with maximum spike width, $5.9 \pm 0.56 \mathrm{~ms}$; 

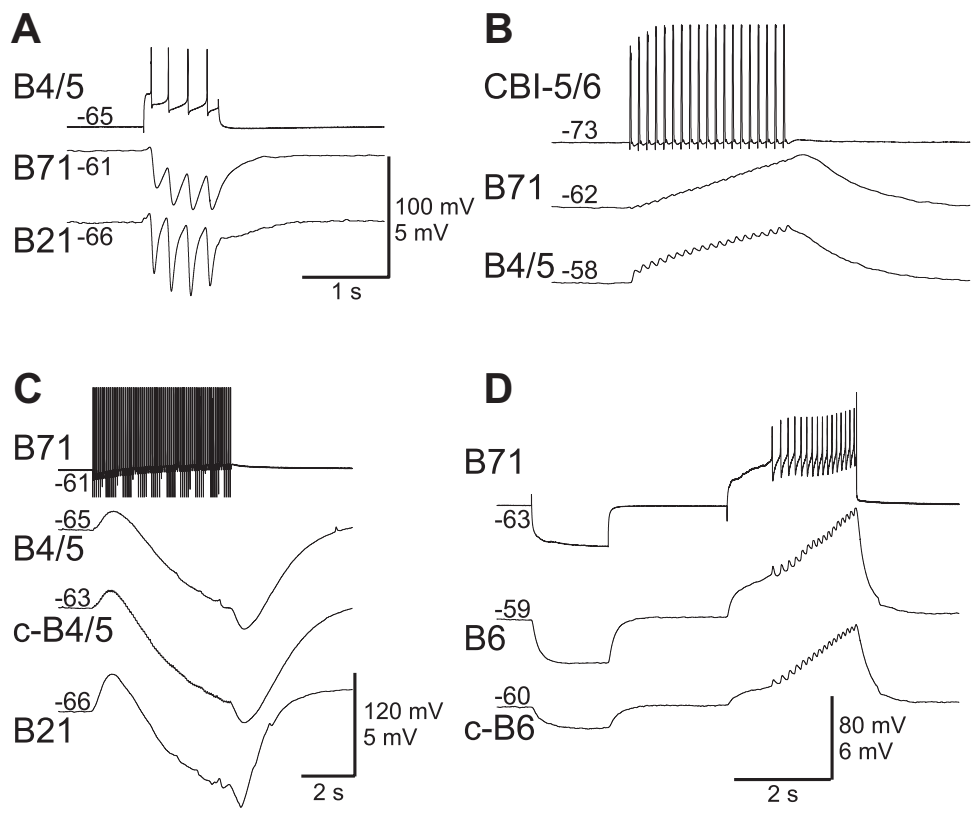

Figure 6. Chemical synaptic connections of B71 with other retraction neurons. $A, B 4 / 5$ elicits one-for-one IPSPs in B71. Also shown is the $B 21$ neuron, which is also inhibited. $B$, Retraction neuron $C B 1-5 / 6$ excites $B 71$ and $B 4 / 5$. C, B71 inhibits B4/5 and B21. No unitary IPSPs can be resolved. $\boldsymbol{D}, \mathrm{B} 71$ is electrically coupled to motoneuron B6. Spikes in B71 elicit large changes in B6 membrane potential, suggesting that B71 may also chemically excite B6. " $c-$ " before cell names in this and the rest of the figures means "contralateral." Numbers at the beginning of traces are membrane potentials (in millivolts).

$\left.t_{(3)}=3.49, p<0.05, n=4\right)$, which is what was observed during the hyper-retraction phase of motor programs (Fig. $1 B$ ). In contrast, when B51 was stimulated, the B8 firing frequency did not show progressive increase, and B8 spikes did not broaden significantly (first spike, $4.47 \pm 0.23 \mathrm{~ms}$, vs the spike with maximum spike width, $\left.4.84 \pm 0.11 \mathrm{~ms} ; t_{(3)}=2.54, p>0.05, n=4\right)$. These data are the first indication that B71 and B51 functions may differ, i.e., B71 is likely to provide a more prominent excitatory drive to B8 during hyper-retraction than B51.

To further assess specific roles of B71 in hyper-retraction, we sought to determine whether B71 activity is necessary for hyperretraction. We stimulated CBI-4 to evoke programs with a hyperretraction phase, and in some programs we hyperpolarized B71 to prevent it from firing. Because hyper-retraction does not always occur, we began B71 hyperpolarization only after we observed spiking in B71. We found that B71 hyperpolarization interrupted the expression of hyper-retraction ( $n=6$; Fig. 9). These data suggest that B71 may be necessary for hyperretraction. B51 is also necessary for hyper-retraction (Jing et al., 2004). Because of the strong coupling between B51 and B71, it is difficult to determine which cell is more critical. However, we designed several stimulation paradigms, as described below, that further distinguish the functions of the two neurons.

Specifically, we determined whether B71 stimulation was sufficient to extend retraction when motor programs elicited by CBI-4 did not have a hyper-retraction. We activated B71 through DC current injection after $\sim 5 \mathrm{~s}$ of retraction and found that this induced robust B8 firing, which became stronger as B71 stimulation progressed (first burst vs the last burst, $5.70 \pm 0.64 \mathrm{~Hz}$ vs $9.45 \pm 0.28 \mathrm{~Hz} ; t_{3}=6.84, p<0.01, n=6$; Fig. 10A2,B2). Interestingly, while $\mathrm{B} 71$ activation was able to drive $\mathrm{B} 8$ activity, neither B51 (Fig. 10A2) nor B64 (B2) showed continued firing, save for a brief period of initial activity. Thus, the ability of B71 to drive B8 did not depend on the activation of B51 or B64, indicating that
B71 by itself was sufficient to act as a critical source of excitatory input to B8 during hyper-retraction.

The absence of continued firing of either B51 or B64 during B71 activation contrasts with normal hyper-retraction when $\mathrm{B} 51, \mathrm{~B} 64$, and $\mathrm{B} 71$ are all coactive throughout this phase. We therefore determined what would happen if we activated cells concurrently. We found that, when we coactivated B71 together with either B51 (Fig. 10A3) or B64 (B3), B8 showed more pronounced firing, particularly during the initial period of activation of these neurons (comparison of the first B8 burst when only B71 is activated vs when both B71 and B51 are activated, $5.01 \pm 1.1 \mathrm{~Hz}$ vs $10.97 \pm 0.15 \mathrm{~Hz}$; $t_{(2)}=$ $6.09, p<0.05, n=3$; when only B71 is activated vs when both B71 and B64 are activated, $6.59 \pm 0.46 \mathrm{~Hz}$ vs $10.31 \pm$ $\left.0.97 \mathrm{~Hz} ; t_{(3)}=3.51, p<0.05, n=4\right)$, suggesting that activation of B51 or B64 can provide additional excitation to B8, either directly or indirectly.

The inability of B71 to recruit continued firing of other critical retraction elements, i.e., B51 or B64, appears to contrast with the actions of B51. Specifically, our previous work indicated that B51 activation extended retraction, and this action was associated with the prolongation of activity in B64 (Jing et al., 2004, their Fig. 9). Here we examined whether B51 extension of retraction was also associated with the activation of B71. We elicited motor programs without a hyperretraction phase through stimulation of CBI-2 or CBI-4. Figure 11 illustrates an experiment in which programs were elicited by CBI-2. In some trials, we activated B51 through DC stimulation of B51 (Fig. 11B), and the retraction phase was extended with strong firing of B8. Importantly, B71 was also activated during the stimulation of B51 $(n=7)$. Since B71 was recruited by B51, we examined the contribution of B71 to the firing frequency of B8. For this, we activated B51 through DC stimulation of B51, and at the same time hyperpolarized B71 to prevent it from firing (Fig. 11C). Under this stimulation paradigm, we found that B8 firing frequency during B51 stimulation and B71 hyperpolarization $(2.46 \pm 0.62 \mathrm{~Hz})$ was significantly lower than B8 firing frequency $\left(8.59 \pm 0.99 \mathrm{~Hz}, t_{(3)}=6.14, p<0.01, n=4\right)$ when only B51 activity was manipulated.

In summary, the synaptic connectivity and functional data together with our previous work (Jing et al., 2004) indicate that the two strongly coupled neurons, B51 and B71, are both important for expression of hyper-retraction. However, B71 is more critical in providing a prominent excitatory drive to radula closure motoneuron B8, whereas B51 appears to be more critical in activating elements of the hyper-retraction circuitry, including B71 and B64. The strong electrical coupling from B51 to both B64 and B71 (Fig. 4A) provides a basis for and supports such a function for B51.

\section{Network functions: B70 and the hyper-retraction phase}

Previously we identified a buccal interneuron, B70, that is active during the later part of retraction and provides inhibition to B8 (Sasaki et al., 2009). However, it was not known 
whether B70 is active during hyperretraction and, if so, whether it determines the activity of B8. To address this question, we first examined B70 activity patterns during CBI-4-elicitied programs with hyper-retraction. We found that B70 started firing during the later part of retraction, when B4/5 activity waned, and that B70 continued firing throughout hyper-retraction (Fig. 12A). Thus, in addition to B51, B71, and B64, B70 is also active during hyper-retraction.

Previously we demonstrated that B8 activity during retraction is subject to concurrent excitatory and inhibitory control, with B70 acting as one major source of inhibition during the later part of retraction (Sasaki et al., 2009). Our data suggest a similar concurrent excitatory and inhibitory control scheme during hyper-retraction since B70 inhibits B8, whereas B71 and B51 excite it.

Consistent with this hypothesis, we found that although B8 activity during hyper-retraction was often very strong (Fig. $1 B$ ), this was not always the case. During some motor programs, $\mathrm{B} 8$ fired at a low frequency (Fig. 12A). To assess a causal role of $\mathrm{B} 70$ in determining $\mathrm{B} 8 \mathrm{ac}-$ tivity, we performed B70 hyperpolarization experiments. We elicited a motor program with a hyper-retraction by stimulating CBI-4. Consistently, strong firing of B70 was associated with a weak firing of B8 (Fig. 12A). However, in the next program, when we hyperpolarized B70 to prevent it from firing, B8 activity during the later part of retraction [as observed by Sasaki et al. (2009)] and during hyper-retraction was increased (Fig. 12B). We quantified B8 firing during hyper-retraction and found that B8 activity when B70 was hyperpolarized (4.73 \pm 0.39 $\mathrm{Hz}$ ) was significantly higher than B8 activity during control $\left(1.13 \pm 0.27 \mathrm{~Hz}, t_{(4)}=13.18, p<0.001, n=5\right)$. Together, the data indicate that B8 activity during hyper-retraction is controlled by both the excitatory neurons B71 and B51, and the inhibitory neuron B70.

\section{Discussion}

Our study indicates that electrical coupling does play a major role in promoting similar firing patterns of coupled neurons in Aplysia feeding microcircuit. Despite this, we showed, surprisingly, that strongly coupled neurons with similar activity patterns and synaptic connections do not necessarily have similar network functions.

\section{Coupling strength and activity patterns}

One primary function of electrical coupling is to promote coordinated firing among coupled neurons (Galarreta and Hestrin, 2001; Bennett and Zukin, 2004). Indeed, electrical coupling was commonly observed among homogeneous neurons, i.e., neurons with similar intrinsic properties and synaptic connectivity. This is particularly true in invertebrates where neurons of the same type,
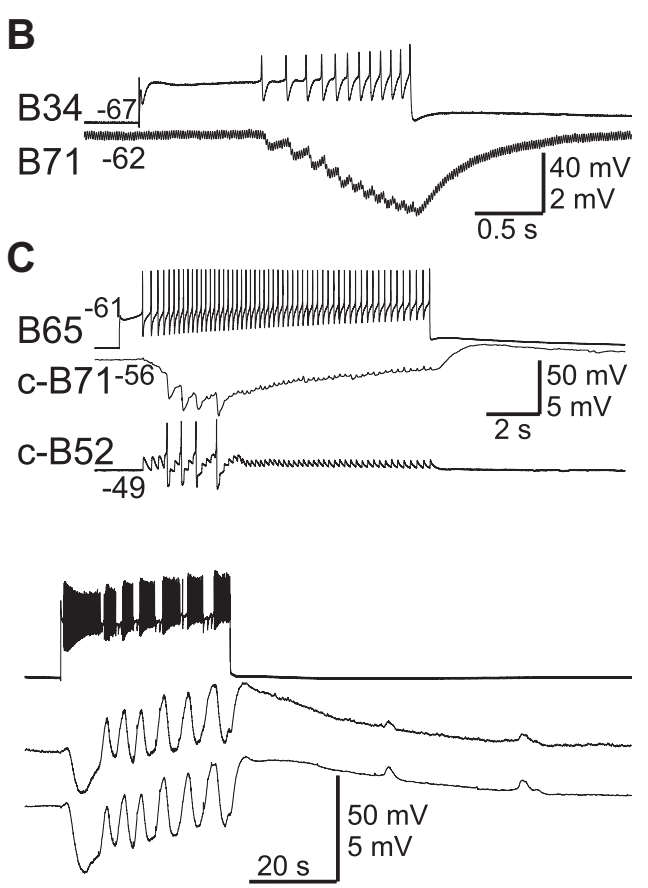

$\mathbf{F}$

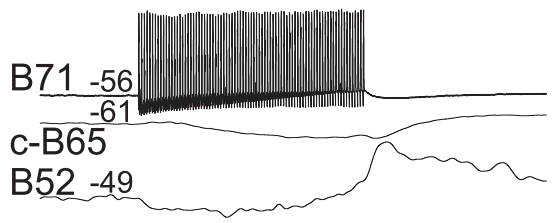

Figure 7. Synaptic connections of $B 71$ with protraction neurons. $\boldsymbol{A}-\boldsymbol{C}$, Protraction interneurons $B 63(\boldsymbol{A}), \mathrm{B} 34(\boldsymbol{B})$, and $B 65(\boldsymbol{C})$ inhibit B71. $A, B, B 63$ and B34 elicit one-for-one IPSPs in B71. B63 also inhibits B52. C, B65 also elicits one-for-one EPSPs in B52, and

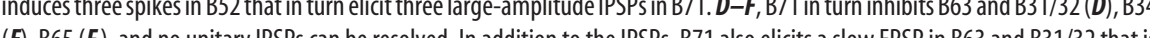
more obvious when $B 71$ is stimulated for prolonged periods ( $\boldsymbol{D}$, right). Recording in $\boldsymbol{B}-\boldsymbol{E}$ were made in high-divalent saline. Numbers at the beginning or the end of traces are membrane potentials (in millivolts).

including contralateral homologues, are electrically coupled and have similar activity patterns (Byrne, 1980, 1983; Getting, 1981; Johnson et al., 1993; Jing and Gillette, 1999; de Bono and Maricq, 2005). Notably, coupling between contralateral homologues promotes bilateral coordination (Plummer and Kirk, 1990; Jing and Gillette, 1999). In mammalian cortical circuits, electrical coupling is commonly observed among GABAergic interneurons of a specific cell type (Galarreta and Hestrin, 2001; Connors and Long, 2004). It is, however, unclear how the specific activity patterns of these neurons compare.

Although less common, electrical coupling between heterogeneous neurons was observed in a number of systems (Johnson et al., 1993; Jing and Gillette, 1999; Susswein et al., 2002; Kristan et al., 2005; Soto-Treviño et al., 2005; Sasaki et al., 2007; Nargeot et al., 2009; Jing et al., 2011; Benjamin, 2012; Roffman et al., 2012), including mammals (Galarreta and Hestrin, 2001; Wilson et al., 2007). The functional role of this electrical coupling is complicated by the fact that these cells are intrinsically different and may also have different synaptic connectivity. Thus, it has been difficult to determine what the specific function of the electrical coupling is. Previous work in well-studied crustacean stomatogastric nervous systems (Johnson et al., 1993, 2005) and leech swimming network (Fan et al., 2005) showed that electrical coupling between heterogeneous elements is present among se- 
A

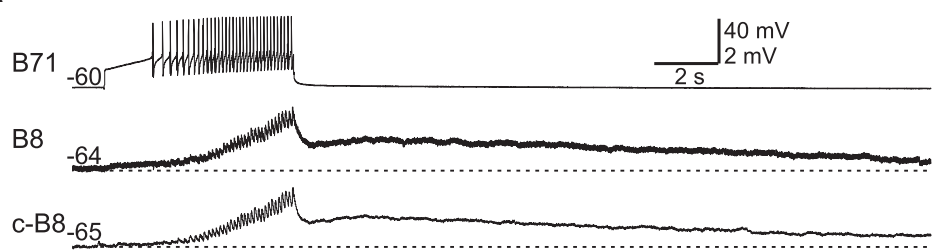

B

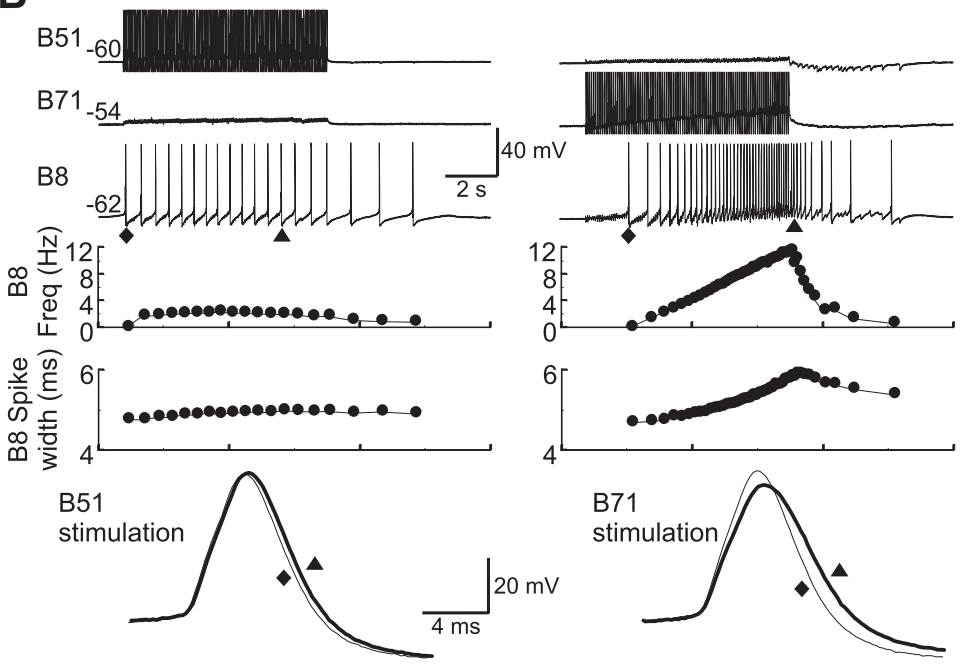

Figure 8. Connections from B71 to radula closure motoneuron B8. $A, B 71$ elicits fast and slow EPSPs in B8 $(n=25)$. The unitary EPSPs are facilitating and become more obvious as B71 stimulation progresses. Dotted line, Resting potentials of $B 8$. Recordings were made in high-divalent saline. $B$, Comparisons of the excitatory actions from B51 (left, $20 \mathrm{~Hz}$ ) and B71 (right, $15 \mathrm{~Hz})$ to B8 ( $n=$ 4). The B71 effect is stronger. Note that when B71, but not B51, is stimulated, B8 firing frequency (Freq) increases progressively, and B8 spikes broaden. Bottom, Enlarged records of B8 show individual spikes of the first one (diamonds, thin lines) and the one with the longest spike width (triangles, thick lines) upon B51 (left) or B71 (right) stimulation. Numbers at the beginning of traces are membrane potentials (in millivolts).

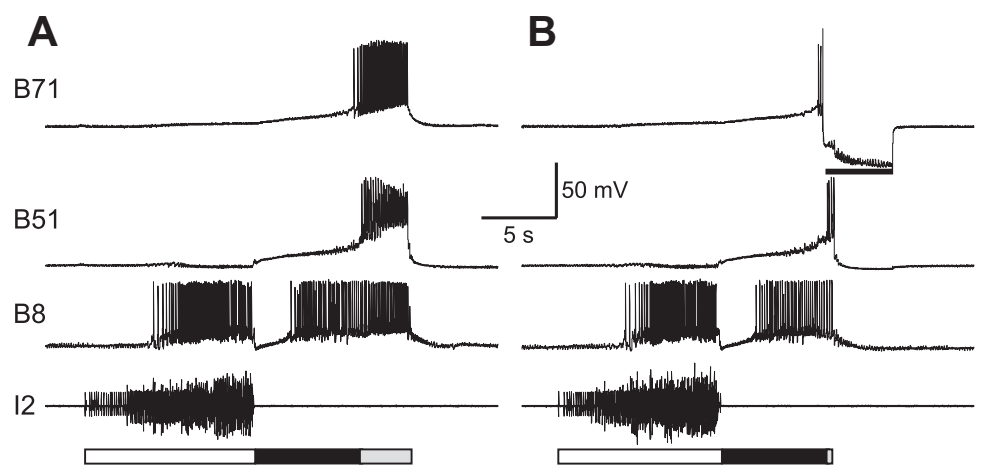

Figure 9. Necessity of $B 71$ for hyper-retraction. $A$, A single cycle of a motor program induced by $C B \mid-4$ stimulation. $C B I-4$ is not shown. $\boldsymbol{B}$, Another cycle of a program elicited by $\mathrm{CBI}-4$, and hyperpolarization of $\mathrm{B} 71$ (bar, $-9 \mathrm{nA})$ prevents expression of hyper-retraction $(n=6)$.

lect members of respective networks, and that it plays important roles in mediating network activity. However, explicit relationships between coupling strengths and activity patterns remain to be determined.

The Aplysia feeding CPG generates motor programs that consist of two antagonistic phases, protraction followed by retraction. Two separate groups of neurons produce protraction and retraction. Electrical coupling is present within both the protraction and retraction circuitry, but is rarely present between neurons serving antagonistic functions. Here we study five retraction neurons that are electrically coupled. The retraction phase shows substantial variability because a hyper-retraction phase, which can be flexibly added to retraction, is sometimes present (Evans and Cropper, 1998; Jing et al., 2004). Indeed, the five heterogeneous neurons show variations in their activity patterns (Fig. 1), which, we hypothesized, might result from differences in coupling strengths.

Consistent with this idea, electrical coupling strength among the five heterogeneous elements differs (Fig. 4, Table 1). Importantly, coupling strength generally matched activity patterns during motor programs. For example, B51 and B71 exhibit one of the strongest coupling ratios and show similar activity patterns, with near synchronous firing during the hyperretraction phase of programs.

However, there is at least one exception to this correlation. B64 and B51 are very strongly coupled, but their activity patterns differ. Such a discrepancy can be explained, in part, by the low spike threshold of B64, which may allow B64 to fire early. Moreover, inhibition from B4/5 to B51 and B71 may serve to delay B51/B71 firing during retraction. Thus, the coupling patterns, combined with chemical synaptic connections and intrinsic properties of these neurons, provide a basis for their distinct activity patterns during the retraction phase of motor programs.

Interestingly, the coupling between the five neurons is mostly asymmetric, i.e., the coupling between pairs of neurons is stronger in one direction than in the opposite direction. Asymmetric coupling has been observed in other systems (Furshpan and Potter, 1959; Giaume and Korn, 1983; Friesen, 1985; Johnson et al., 1993; Jing and Gillette, 1999; Kawano et al., 2011; Wu et al., 2011). In some cases it results from rectifying electrical coupling (i.e., heterotypic gap junctions) (Phelan et al., 2008), and in others differences in intrinsic properties (Bennett, 1966; Johnson et al., 1993). Here, we show that asymmetrical coupling between B64 and B51, B64 and B71, and B51 and B71 neuron pairs is not due to rectifying electrical coupling, but rather, is likely due to differences in intrinsic properties, i.e., input resistance. This further supports the heterogeneity of these neurons.

\section{Coupling strength and network functions}

To examine functions of these electrically coupled neurons, we determined their impact on the activity of B8, a critical motoneuron that controls radula closing during feeding and is essential for manipulating food (Morton and Chiel, 1993a,b; Orekhova et al., 2001). From this perspective, B8 excitatory neurons, B51, B71, and B64, are strongly coupled, whereas B8 inhibitory neurons, 

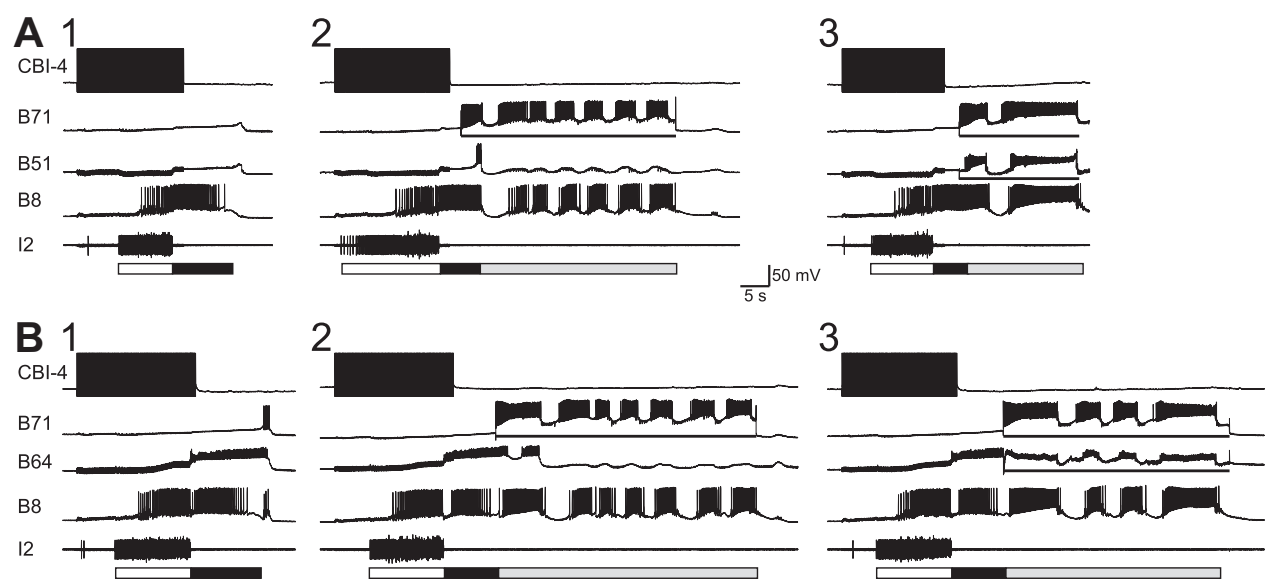

Figure 10. B71 stimulation in motor programs elicited by CBI-4 does not recruit continued firing of B51 or B64.A1, B1, A single cycle of a motor program elicited by CBI-4 without hyper-retraction. $A 2, B 2$, Activation of $B 71$ (bars) induces strong firing in B8 reminiscent of $B 8$ firing in hyper-retraction, and neither $B 51(A 2 ; n=3)$ nor $B 64(B 2 ; n=4)$ is recruited to fire continuously, save for a brief period of initial activity. $A 3, B 3$, Coactivation (bars) of $B 51(A 3)$ or $B 64(B 3)$ with $B 71$ does enhance $B 8$ activity. All DC currents applied were $8 \mathrm{nA}$.
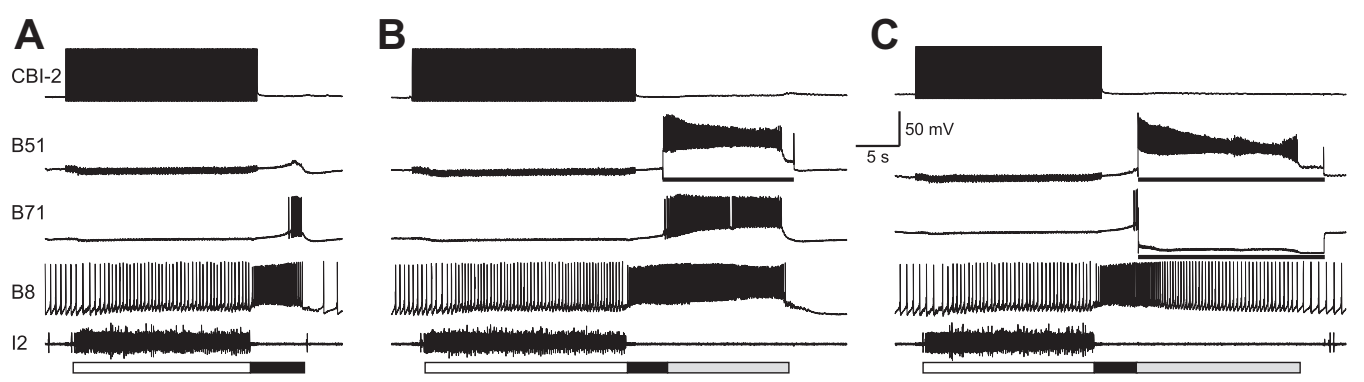

Figure 11. B51 stimulation recruits $B 71$ in motor programs. $A$, A single cycle of a motor program elicited by stimulation of CBI-2. B, Activation of $B 51$ (bar, $14 \mathrm{nA})$ toward the later part of retraction induces hyper-retraction-like activity that is accompanied by strong firing in $B 71(n=7)$ and B8. C, Simultaneous activation of $B 51(\mathrm{bar}, 16 \mathrm{nA})$ and hyperpolarization of $\mathrm{B} 71(\mathrm{bar},-8 \mathrm{nA})$ result in weaker firing in B8 ( $n=4)$ compared to that in $\boldsymbol{B}$.

B4/5 and especially B70, are weakly coupled to the other neurons. Thus, the overall patterns of coupling strengths support the notion that functionally related neurons are more strongly coupled.

Previous work (Hurwitz et al., 1997; Jing and Weiss, 2001, 2002; Sasaki et al., 2009) showed that B8 activity during protraction and retraction is subject to concurrent excitatory and inhibitory control. Here, the findings that B70 is also active during hyper-retraction extend concurrent excitatory and inhibitory control to hyper-retraction, because during hyperretraction, B8 activity is not only controlled by excitatory neurons B51 and B71, but also by inhibitory neuron B70. Thus, B8 activity appears to be controlled by concurrent excitation and inhibition throughout a cycle of feeding motor programs. This form of synaptic control may enable the flexible expression of various levels of B8 activity during the generation of different forms of behaviorally relevant motor programs (Morton and Chiel, 1993a,b; Jing et al., 2004).

Do functionally related neurons necessarily have similar outputs? Perhaps, the least expected finding of this study concerns the differential roles of B51 and B71 in controlling B8 activity, and was only uncovered after detailed analysis of their functions.

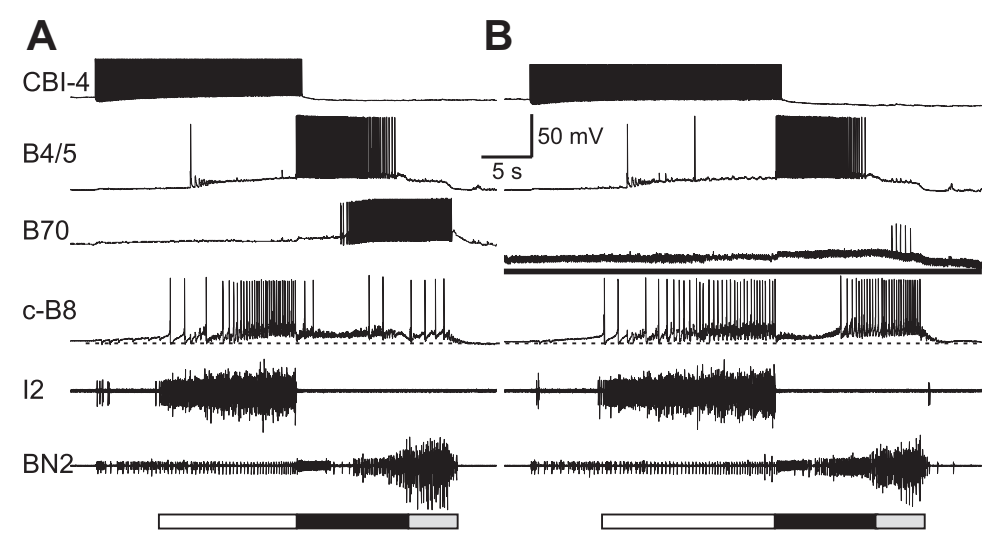

Figure 12. B70 suppresses B8 activity during hyper-retraction. $A, A$ single cycle of a motor program elicited by $C B \mid-4 . B 70$ is active during the later part of retraction and hyper-retraction. $B, B 70$ hyperpolarization $(\mathrm{bar},-6 \mathrm{nA})$ leads to higher-frequency firing in B8 during the later part of retraction and hyper-retraction $(n=5)$. BN2, Buccal nerve 2.

B51 and B71 are strongly coupled, show identical firing patterns, and provide chemical excitation to B8, all of which may imply that both neurons may make a prominent contribution to B8 activation. Yet, our study shows that they appear to exert differential actions. Hyperpolarization of either B51 (Jing et al., 2004) or B71 prevents the expression of hyper-retraction and B8 stops firing. Strong coupling between B51 and B71 makes it difficult for the hyperpolarization experiments to discern specific contributions of the two neurons to hyper-retraction and B8 firing. However, several of our experimental paradigms reveal that both 


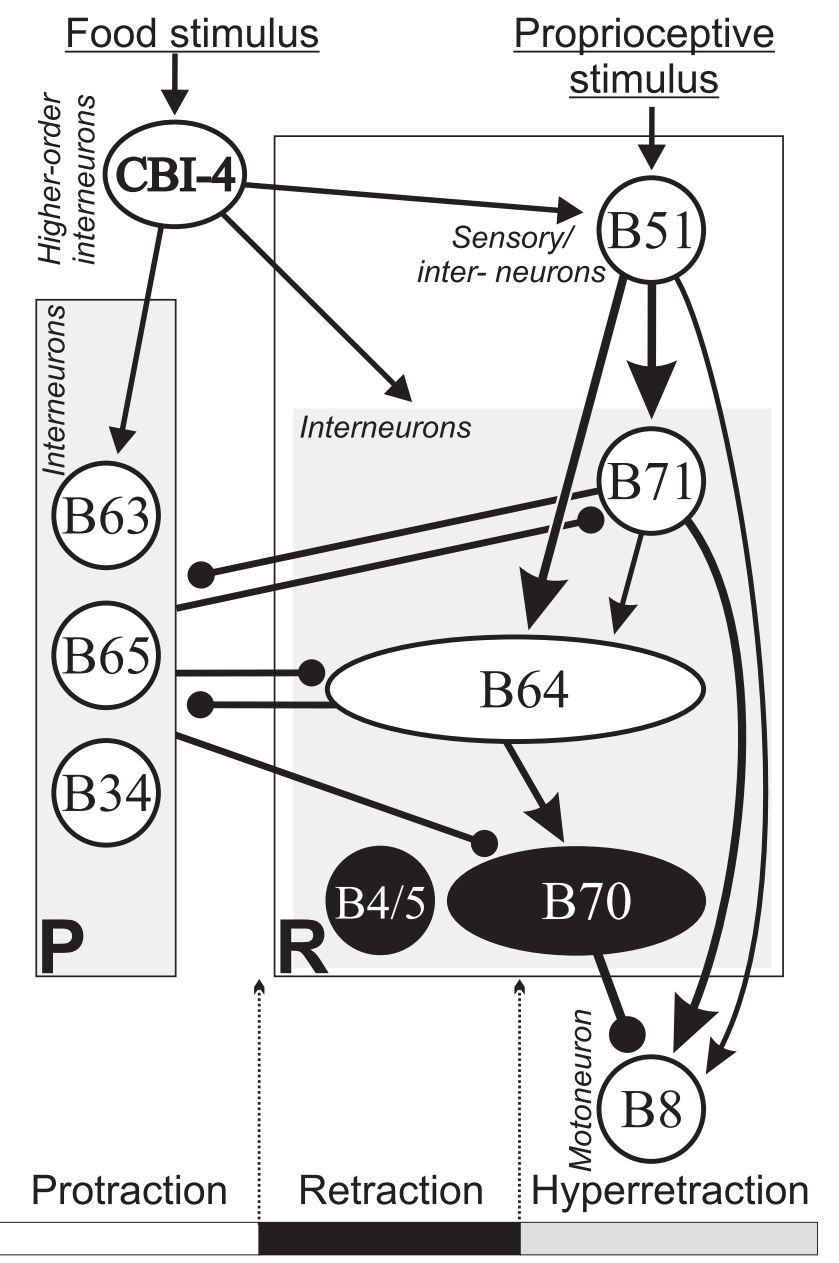

Figure 13. A simplified diagram of the feeding microcircuit with an emphasis on the functional connectivity that is responsible for generating hyper-retraction as well as B8 activity during hyper-retraction. Cells shown in expanded ovals illustrate their activity throughout retraction, including hyper-retraction (B64), or during the later part of retraction and hyperretraction (B70). Although $B 8$ can also be active during protraction and retraction, $B 8$ is shown only in hyper-retraction because this is the focus of the present work. $B 4 / 5$ is active during the earlier part of retraction. Mutual inhibition between protraction $(P)$ interneurons (e.g., B63, $B 65, B 34)$ and retraction (R) interneurons (B64, B71) enables the generation of antagonist protraction versus retraction/hyper-retraction phases. The B51 neuron, receiving proprioceptive inputs from the feeding motor apparatus, i.e., the buccal mass, during feeding, plays a major role in exciting interneurons B71 and B64, and therefore the generation of hyperretraction. $B 71$, in turn, provides strong excitation to $B 8$. $B 64$ also provides excitation to $B 70$, which inhibits B8. Thus, B8 activity is controlled by both excitatory and inhibitory interneurons. $\mathrm{B} 51$ and the three interneurons $\mathrm{B} 71, \mathrm{~B} 64$, and $\mathrm{B} 70$ may also receive inputs from $\mathrm{CBI}-4$, which is activated by food stimulus originating from the head and, when active, can in turn evoke motor programs with hyper-retraction. Different synaptic strengths are illustrated with various sizes of line thickness. Not all connections are shown, for clarity. For example, the inhibitions of all retraction neurons by B4/5 are omitted (but see Fig. 4B). Arrows, Chemical or electrical excitation; closed circles, inhibition.

neurons contribute to the activation of B8, but B51 functions primarily to drive B64 and B71, while B71 functions preferentially to drive B8 (Fig. 13). Strong asymmetric coupling from B51 to B64 and B71 is consistent with this notion.

Previous work (Evans and Cropper, 1998; Jing et al., 2004; Baxter and Byrne, 2006) and this study provide an integrative understanding of how the microcircuit controls hyper-retraction (Fig. 13). Because B51 receives proprioceptive inputs from the feeding apparatus, i.e., the buccal mass, as an activator of B64 and B71, B51 may transmit sensory information to them. All of these neurons may also integrate inputs from higher-order neuron CBI-4, which is activated by food stimulus originating from the head. Finally, activity in B71/B51, B70, and B64 would determine the actual motor outputs during hyper-retraction. Functional differentiation of B51 and B71 is further consistent with and reinforces a suggestion for a modular organization of the Aplysia feeding motor network (Jing et al., 2004; Jing and Weiss, 2005). Modular organization may also operate in vertebrate motor circuits (Stein and Smith, 1997; Bizzi et al., 2000).

\section{Summary}

Our study indicates that it is fruitful to quantify the coupling ratios among electrically coupled heterogeneous elements in microcircuits. This information provides a basis for the characterization of relative contributions of electrical and chemical synaptic connections, and intrinsic properties of these circuit elements to their firing patterns during network activity. We expect that our work is relevant to many other model microcircuits. In particular, our study generally supports the idea that functionally related neurons are coupled more strongly. However, consistent with previous work in other systems (Marder and Bucher, 2007; Weaver et al., 2010), it shows that, in addition to electrical coupling, both intrinsic properties and chemical connections of circuit elements also fine-tune their activity patterns.

More importantly, we show that specific network functions of electrically coupled heterogeneous neurons can be very complex and difficult to discern. Thus, network functions of electrically coupled network elements, and possibly also for elements that are not coupled, cannot be simply inferred from their activity patterns, or even their synaptic connectivity, particularly considering that network elements in many microcircuits often make more than one connection. Rather, our study offers a cautionary tale for functional studies that rely on observing activity and/or anatomical connectivity of the brain (Lichtman et al., 2008; DeFelipe, 2010; Kelly et al., 2012), and indicates that it is essential to thoroughly analyze network functions of specific neurons. In this regard, the small microcircuit of Aplysia proves to be particularly advantageous in understanding how these neurons may fulfill specific network functions.

\section{References}

Baxter DA, Byrne JH (2006) Feeding behavior of Aplysia: a model system for comparing cellular mechanisms of classical and operant conditioning. Learn Mem 13:669-680. CrossRef Medline

Benjamin PR (2012) Distributed network organization underlying feeding behavior in the mollusk Lymnaea. Neural Syst Circuits 2:4. CrossRef Medline

Bennett MV (1966) Physiology of electrotonic junctions. Ann N Y Acad Sci 137:509-539. CrossRef

Bennett MV, Zukin RS (2004) Electrical coupling and neuronal synchronization in the Mammalian brain. Neuron 41:495-511. CrossRef Medline

Bizzi E, Tresch MC, Saltiel P, d'Avella A (2000) New perspectives on spinal motor systems. Nat Rev Neurosci 1:101-108. CrossRef Medline

Byrne JH (1980) Quantitative aspects of ionic conductance mechanisms contributing to firing pattern of motor cells mediating inking behavior in Aplysia californica. J Neurophysiol 43:651-668. Medline

Byrne JH (1983) Identification and initial characterization of a cluster of command and pattern-generating neurons underlying respiratory pumping in Aplysia californica. J Neurophysiol 49:491-508. Medline

Chow CC, Kopell N (2000) Dynamics of spiking neurons with electrical coupling. Neural Comput 12:1643-1678. CrossRef Medline

Church PJ, Lloyd PE (1994) Activity of multiple identified motor neurons recorded intracellularly during evoked feedinglike motor programs in Aplysia. J Neurophysiol 72:1794-1809. Medline

Connors BW, Long MA (2004) Electrical synapses in the mammalian brain. Annu Rev Neurosci 27:393-418. CrossRef Medline 
Cropper EC, Evans CG, Hurwitz I, Jing J, Proekt A, Romero A, Rosen SC (2004) Feeding neural networks in the mollusc Aplysia. Neurosignals 13:70-86. CrossRef Medline

de Bono M, Maricq AV (2005) Neuronal substrates of complex behaviors in C. elegans. Annu Rev Neurosci 28:451-501. CrossRef Medline

DeFelipe J (2010) From the connectome to the synaptome: an epic love story. Science 330:1198-1201. CrossRef Medline

De Vries G, Sherman A, Zhu HR (1998) Diffusively coupled bursters: effects of cell heterogeneity. Bull Math Biol 60:1167-1200. CrossRef Medline

Evans CG, Cropper EC (1998) Proprioceptive input to feeding motor programs in Aplysia. J Neurosci 18:8016-8031. Medline

Fan RJ, Marin-Burgin A, French KA, Otto Friesen W (2005) A dye mixture (Neurobiotin and Alexa 488) reveals extensive dye-coupling among neurons in leeches; physiology confirms the connections. J Comp Physiol A Neuroethol Sens Neural Behav Physiol 191:1157-1171. CrossRef Medline

Friesen WO (1985) Neuronal control of leech swimming movements: interactions between cell 60 and previously described oscillator neurons. J Comp Physiol A Neuroethol Sens Neural Behav Physiol 156:231-242. CrossRef

Furshpan EJ, Potter DD (1959) Transmission at the giant motor synapses of the crayfish. J Physiol 145:289-325. Medline

Galarreta M, Hestrin S (2001) Electrical synapses between GABA-releasing interneurons. Nat Rev Neurosci 2:425-433. CrossRef Medline

Gardner D (1977) Interconnections of identified multiaction interneurons in buccal ganglia of Aplysia. J Neurophysiol 40:349-361. Medline

Getting PA (1981) Mechanisms of pattern generation underlying swimming in Tritonia. I. Neuronal network formed by monosynaptic connections. J Neurophysiol 46:65-79. Medline

Giaume C, Korn H (1983) Bidirectional transmission at the rectifying electrotonic synapse: a voltage-dependent process. Science 220:84-87. CrossRef Medline

Hurwitz I, Susswein AJ (1996) B64, a newly identified central pattern generator element producing a phase switch from protraction to retraction in buccal motor programs of Aplysia californica. J Neurophysiol 75:1327-1344. Medline

Hurwitz I, Goldstein RS, Susswein AJ (1994) Compartmentalization of pattern-initiation and motor functions in the B31 and B32 neurons of the buccal ganglia of Aplysia californica. J Neurophysiol 71:1514-1527. Medline

Hurwitz I, Kupfermann I, Susswein AJ (1997) Different roles of neurons B63 and B34 that are active during the protraction phase of buccal motor programs in Aplysia californica. J Neurophysiol 78:1305-1319. Medline

Jefferys JG (1995) Nonsynaptic modulation of neuronal activity in the brain: electric currents and extracellular ions. Physiol Rev 75:689-723. Medline

Jing J, Gillette R (1999) Central pattern generator for escape swimming in the notaspid sea slug Pleurobranchaea californica. J Neurophysiol 81:654667. Medline

Jing J, Weiss KR (2001) Neural mechanisms of motor program switching in Aplysia. J Neurosci 21:7349-7362. Medline

Jing J, Weiss KR (2002) Interneuronal basis of the generation of related but distinct motor programs in Aplysia: implications for current neuronal models of vertebrate intralimb coordination. J Neurosci 22:6228-6238. Medline

Jing J, Weiss KR (2005) Generation of variants of a motor act in a modular and hierarchical motor network. Curr Biol 15:1712-1721. CrossRef Medline

Jing J, Cropper EC, Hurwitz I, Weiss KR (2004) The construction of movement with behavior-specific and behavior-independent modules. J Neurosci 24:6315-6325. CrossRef Medline

Jing J, Gillette R, Weiss KR (2009) Evolving concepts of arousal: insights from simple model systems. Rev Neurosci 20:405-427. Medline

Jing J, Sweedler JV, Cropper EC, Alexeeva V, Park JH, Romanova EV, Xie F, Dembrow NC, Ludwar BC, Weiss KR, Vilim FS (2010) Feedforward compensation mediated by the central and peripheral actions of a single neuropeptide discovered using representational difference analysis. J Neurosci 30:16545-16558. CrossRef Medline

Jing J, Sasaki K, Perkins MH, Siniscalchi MJ, Ludwar BC, Cropper EC, Weiss KR (2011) Coordination of distinct motor structures through remote axonal coupling of projection interneurons. J Neurosci 31:15438-15449. CrossRef Medline

Johnson BR, Peck JH, Harris-Warrick RM (1993) Amine modulation of electrical coupling in the pyloric network of the lobster stomatogastric ganglion. J Comp Physiol A Neuroethol Sens Neural Behav Physiol 172: 715-732. Medline

Johnson BR, Schneider LR, Nadim F, Harris-Warrick RM (2005) Dopamine modulation of phasing of activity in a rhythmic motor network: contribution of synaptic and intrinsic modulatory actions. J Neurophysiol 94:3101-3111. CrossRef Medline

Kawano T, Po MD, Gao S, Leung G, Ryu WS, Zhen M (2011) An imbalancing act: gap junctions reduce the backward motor circuit activity to bias $C$. elegans for forward locomotion. Neuron 72:572-586. CrossRef Medline

Kelly C, Biswal BB, Craddock RC, Castellanos FX, Milham MP (2012) Characterizing variation in the functional connectome: promise and pitfalls. Trends Cogn Sci 16:181-188. CrossRef Medline

Kepler TB, Marder E, Abbott LF (1990) The effect of electrical coupling on the frequency of model neuronal oscillators. Science 248:83-85. CrossRef Medline

Kristan WB Jr, Calabrese RL, Friesen WO (2005) Neuronal control of leech behavior. Prog Neurobiol 76:279-327. CrossRef Medline

Lichtman JW, Livet J, Sanes JR (2008) A technicolour approach to the connectome. Nat Rev Neurosci 9:417-422. CrossRef Medline

Ma M, Koester J (1996) The role of $\mathrm{K}+$ currents in frequency-dependent spike broadening in Aplysia R20 neurons: a dynamic-clamp analysis. J Neurosci 16:4089-4101. Medline

Marder E (2009) Electrical synapses: rectification demystified. Curr Biol 19: R34-R35. CrossRef Medline

Marder E, Bucher D (2007) Understanding circuit dynamics using the stomatogastric nervous system of lobsters and crabs. Annu Rev Physiol 69: 291-316. CrossRef Medline

Morgan PT, Jing J, Vilim FS, Weiss KR (2002) Interneuronal and peptidergic control of motor pattern switching in Aplysia. J Neurophysiol 87:49-61. Medline

Morton DW, Chiel HJ (1993a) In vivo buccal nerve activity that distinguishes ingestion from rejection can be used to predict behavioral transitions in Aplysia. J Comp Physiol A Neuroethol Sens Neural Behav Physiol 172:17-32. CrossRef

Morton DW, Chiel HJ (1993b) The timing of activity in motor neurons that produce radula movements distinguishes ingestion from rejection in $A p$ lysia. J Comp Physiol A Neuroethol Sens Neural Behav Physiol 173:519536. Medline

Mozzachiodi R, Lorenzetti FD, Baxter DA, Byrne JH (2008) Changes in neuronal excitability serve as a mechanism of long-term memory for operant conditioning. Nat Neurosci 11:1146-1148. CrossRef Medline

Nargeot R, Baxter DA, Byrne JH (1997) Contingent-dependent enhancement of rhythmic motor patterns: an in vitro analog of operant conditioning. J Neurosci 17:8093-8105. Medline

Nargeot R, Baxter DA, Byrne JH (1999) In vitro analog of operant conditioning in Aplysia. II. Modifications of the functional dynamics of an identified neuron contribute to motor pattern selection. J Neurosci 19: 2261-2272. Medline

Nargeot R, Le Bon-Jego M, Simmers J (2009) Cellular and network mechanisms of operant learning-induced compulsive behavior in Aplysia. Curr Biol 19:975-984. CrossRef Medline

Orekhova IV, Jing J, Brezina V, DiCaprio RA, Weiss KR, Cropper EC (2001) Sonometric measurements of motor-neuron-evoked movements of an internal feeding structure (the radula) in Aplysia. J Neurophysiol 86: 1057-1061. Medline

Phelan P, Goulding LA, Tam JL, Allen MJ, Dawber RJ, Davies JA, Bacon JP (2008) Molecular mechanism of rectification at identified electrical synapses in the Drosophila giant fiber system. Curr Biol 18:1955-1960. CrossRef Medline

Plummer MR, Kirk MD (1990) Premotor neurons B51 and B52 in the buccal ganglia of Aplysia californica: synaptic connections, effects on ongoing motor rhythms, and peptide modulation. J Neurophysiol 63:539-558. Medline

Roffman RC, Norris BJ, Calabrese RL (2012) Animal-to-animal variability of connection strength in the leech heartbeat central pattern generator. J Neurophysiol 107:1681-1693. CrossRef Medline

Rosen SC, Teyke T, Miller MW, Weiss KR, Kupfermann I (1991) Identification and characterization of cerebral-to-buccal interneurons implicated in the control of motor programs associated with feeding in Aplysia. J Neurosci 11:3630-3655. Medline

Rosen SC, Miller MW, Evans CG, Cropper EC, Kupfermann I (2000) Diverse synaptic connections between peptidergic radula mechanoafferent 
neurons and neurons in the feeding system of Aplysia. J Neurophysiol 83:1605-1620. Medline

Sasaki K, Due MR, Jing J, Weiss KR (2007) Feeding CPG in Aplysia directly controls two distinct outputs of a compartmentalized interneuron that functions as a CPG element. J Neurophysiol 98:3796-3801. CrossRef Medline

Sasaki K, Brezina V, Weiss KR, Jing J (2009) Distinct inhibitory neurons exert temporally specific control over activity of a motoneuron receiving concurrent excitation and inhibition. J Neurosci 29:11732-11744. CrossRef Medline

Sherman A, Rinzel J (1992) Rhythmogenic effects of weak electrotonic coupling in neuronal models. Proc Natl Acad Sci U S A 89:2471-2474. CrossRef Medline

Soto-Treviño C, Rabbah P, Marder E, Nadim F (2005) Computational model of electrically coupled, intrinsically distinct pacemaker neurons. J Neurophysiol 94:590-604. CrossRef Medline

Stein PS, Smith JL (1997) Neural and biomechanical control strategies for different forms of vertebrate hindlimb motor tasks. In: Neurons, networks, and motor behavior (Stein PSG, Grillner S, Selverston AI, Stuart DG, eds), pp 61-73. Cambridge, MA: MIT.

Susswein AJ, Hurwitz I, Thorne R, Byrne JH, Baxter DA (2002) Mechanisms underlying fictive feeding in Aplysia: coupling between a large neuron with plateau potentials activity and a spiking neuron. J Neurophysiol 87:2307-2323. Medline

Teyke T, Rosen SC, Weiss KR, Kupfermann I (1993) Dopaminergic neuronB20 generates rhythmic neuronal activity in the feeding motor circuitry of Aplysia. Brain Res 630:226-237. CrossRef Medline

Weaver AL, Roffman RC, Norris BJ, Calabrese RL (2010) A role for compromise: synaptic inhibition and electrical coupling interact to control phasing in the leech heartbeat CPG. Front Behav Neurosci 4:38. Medline

Wilson CJ, Callaway JC (2000) Coupled oscillator model of the dopaminergic neuron of the substantia nigra. J Neurophysiol 83:3084-3100. Medline

Wilson JM, Cowan AI, Brownstone RM (2007) Heterogeneous electrotonic coupling and synchronization of rhythmic bursting activity in mouse $\mathrm{Hb} 9$ interneurons. J Neurophysiol 98:2370-2381. CrossRef Medline

Wu CL, Shih MF, Lai JS, Yang HT, Turner GC, Chen L, Chiang AS (2011) Heterotypic gap junctions between two neurons in the Drosophila brain are critical for memory. Curr Biol 21:848-854. CrossRef Medline

Wu JS, Vilim FS, Hatcher NG, Due MR, Sweedler JV, Weiss KR, Jing J (2010) Composite modulatory feedforward loop contributes to the establishment of a network state. J Neurophysiol 103:2174-2184. CrossRef Medline 